\title{
LITERATURA PARAENSE DE AUTORIA FEMININA: UMA PERSPECTIVA DIACRÔNICA
}

\author{
PARENSE LITERATURE OF FEMALE AUTHORS: A DIACHRONIC PERSPECTIVE
}

Francisco Rodrigues da Silva Neto
\[ \begin{array}{c}\text { http://lattes.cnpq.br/9035449857181354 } \\ \text { https://orcid.org/0000-0002-0249-1945 }\end{array} \]

Claudia Valéria França Vidal ${ }^{2}$

http://lattes.cnpq.br/1297160868350769

https://orcid.org/0000-0003-1035-1894

Recebido em: 13 de agosto de 2019.

Aprovado em: 18 de março de 2020.

RESUMO: A presença da mulher na literatura enquanto produtora de textos escritos é bem mais tardia e numericamente inferior do que a do homem devido a uma série de fatores histórico-sociais. A discussão em torno deste descompasso toma força a partir do surgimento da linha da crítica literária feminista na década de 1970 nos Estados Unidos. Uma de suas vertentes, a ginocrítica, tem por finalidade pesquisar o corpus literário produzido por mulheres, até então praticamente ignorado pela crítica tradicional predominantemente masculina, bem como, a formação de um cânone alternativo. Esta tendência de estudos, atualmente mais conhecida sob a rubrica da crítica de gênero, foi replicandose para outros países e suas respectivas literaturas. No que toca à literatura brasileira, muitos trabalhos têm sido produzidos sobre o assunto nas últimas três décadas. Este artigo propõe apresentar uma revisão diacrônica da presença da mulher nas letras paraenses do século XX ao momento atual, analisando a relação entre gênero, produção literária, mercado editorial e invisibilidade. Observou-se que o Grupo de Estudos e Pesquisas Eneida de Moraes tem encabeçado estas investigações. Também foi possível constatar que o advento da era digital e a cibercultura abriram novas possibilidades para a publicação de mais escritoras, para a formação de redes de divulgação e para a investigação acerca do objeto proposto.

Palavras-chave: Gênero. Autoria feminina. Memória. Era Digital. Literatura Paraense.

\begin{abstract}
The presence of woman in literature as a producer of written texts is much later and numerically inferior to that of man due to a series of historical and social factors. The discussion about this mismatch gains strength from the emergence of the feminist literary criticism line in the 1970s in the United States. One of its trends, the gynocritic, has the purpose of researching the literary corpus produced by women, hitherto largely ignored by the predominantly male traditional critique, as well as the formation of an alternative canon. This trend of studies, now better known under the rubric of gender
\end{abstract}

\footnotetext{
${ }^{1}$ Escola Superior da Amazônia (ESAMAZ). Historiador. Mestre em Antropologia e Doutor em Ciências Sócio-Ambientais junto ao Programa de Pós-graduação em Desenvolvimento Sustentável do Trópico Úmido (NAEA/UFPA). Docente no curso de Bacharelado em Direito. E-mail: fneto21@,hotmail.com

2 Professora do curso de Tecnologia em Produção Multimídia (FAV/ICA) da Universidade Federal do Pará (UFPA). Mestra em Letras: Estudos Linguísticos e Literários (UFPA). E-mail: claudiavidal35@gmail.com
} 
criticism, has been replicated in other countries and their respective literatures. Regarding Brazilian literature, many works have been produced on the subject in the last three decades. This article proposes to present a diachronic review of the presence of woman in Pará's literature from the 20th century to the present moment analyzing the relation among gender, literary production, publishing market and invisibility. It was observed that the Eneida de Moraes Studies and Research Group has headed these investigations. It was also possible to observe that the digital age and cyberculture advent opened new possibilities for the publication of more writers, the formation of dissemination networks and for researching about the proposed object.

Keywords: Gender. Female authorship. Memory. Digital age. Literature from Pará.

\section{INTRODUÇÃO}

A tradição literária ocidental iniciou-se cerca de oito séculos antes do início da era comum. No entanto, ao longo de todo este tempo, a exceção de exemplos esparsos, como a poeta grega Safo de Lesbos, que viveu há 2600 anos, e a espanhola Leonor López de Córdoba, falecida em 1430, quase não se tem notícia de mulheres publicando até o século XVIII.

Tendo como marco inicial a publicação de Sexual Politics de Kate Millet em 1970, a crítica literária feminista, segundo Bonnici (2007, p. 49), propõe duas vertentes: a leitura feminista de textos já pertencentes ao cânone ocidental, majoritariamente de autoria masculina, e a ginocrítica. Esta última, tem como principal objetivo a "redescoberta e reavaliação de escrita de autoria feminina" com vistas à ampliação do cânone. Ademais, se propõe a investigar as marcas que distinguem a constituição das escritas masculina e feminina.

Este segundo objeto da ginocrítica é questionado por alguns autores que defendem que "O autor e as vozes colocadas na obra literária devam ser desvinculados” (BONICCI, 2007, p. 50) e que uma mulher pode, através de um exercício de alteridade, ler e escrever como um homem (e vice-versa). Este artigo, porém, alinha-se com a ideia de que tais casos seriam simulacros (MAINGUENEAU, 2005) ${ }^{3}$, portanto, com forte tendência a deixar transparecer a real identidade discursiva de seus autores em algum momento, e com o pressuposto de Barthes (1973 apud BRANCO E BRANDÃO, 2004) de que não há como um indivíduo se deslocar totalmente de seu lugar de fala.

O estudo de Branco e Brandão (2004), no qual, tomando por base a psicanálise lacaniana, tece ensaios sobre doze textos literários de autoria masculina e dez de autoria feminina, sugere que, mesmo que não haja características intrínsecas a esta segunda, há, certamente, elementos recorrentes. Os dois mais evidentes são a preferência pelo gênero memorialista (cartas, diários, autobiografias) e a ênfase em relações interpessoais no âmbito privado (amor, família, filhos). Pode-se também observar que se trata de uma escrita lacunar, onde mais se insinua do que diz, frequentemente através de uma verborragia repleta de reiterações, descrições minuciosas de coisas aparentemente triviais e o profuso emprego de advérbios, adjetivos e relações sinestésicas. Além disso, há uma pronunciada ênfase na sexualidade, seja ela vivida ou reprimida, possivelmente como uma maneira de escapar à repressão cultural (fugir à lei do pai) e, ainda, como forma de compartilhar o misterioso gozo feminino ${ }^{4}$.

\footnotetext{
${ }^{3}$ Para Maingueneau, quando dois discursos antagonistas se encontraram, para que um compreenda o outro é necessário que haja uma espécie de tradução, ou seja, um discurso somente compreende o outro a partir de suas próprias categorias de análise, de simulacros.

${ }^{4}$ Lacan postula que "o gozo feminino, ao contrário do masculino, não é observável (...) Deste gozo apenas se sabe o que o sujeito que o experimentou declara” (VIDAL, 2017, p. 423).
} 
É provável que estas marcas se devam aos papéis restritivos historicamente destinados às mulheres, uma vez que é importante não perder de vista que

[...] por motivos mitológicos, antropológicos, sociológicos e históricos, a mulher foi excluída do mundo da escrita - só podendo introduzir seu nome na história europeia, por assim dizer, através de arestas e frestas que conseguiu abrir através de seu aprendizado de ler e escrever em conventos (LOBO, 1999, p. 5)

Nesta perspectiva, cabe determo-nos por um momento no conceito de silenciamento proposto por Michael Pollack em seu artigo intitulado: "Memória, Esquecimento e Silêncio" a partir dos estudos de Halbwachs (2006) de quem utiliza o conceito de Memória Coletiva. Para Pollak (1989) o silêncio e o discurso, as lembranças e os esquecimentos cumprem objetivos diversos, seja no plano individual ou coletivo, pois a memória é construída seletivamente pelo coletivo, ou seja, é uma construção social.

A bem da verdade, toda memória é, até certo ponto, coletiva, pois sua constituição é permeada pelo social, como explica Bosi (1994, p. 419),

Mal termina a percepção, as lembranças já começam a modificá-la: experiências, hábitos, afetos, convenções vão trabalhar a matéria da memória. Um desejo de explicação atua sobre o presente e sobre o passado, integrando suas experiências nos esquemas pelos quais a pessoa norteia sua vida. (grifos nossos)

As convenções e os esquemas são aprendidos na interação entre os membros de um grupo social. Assim como "cada memória individual é um ponto de vista sobre a memória coletiva" (BOSI, 1994, p. 413), a memória coletiva é formada pelo conjunto das memórias individuais, o que torna difícil determinar os limites entre uma e outra. Trata-se, portanto, de uma relação dialética.

Afirmar que a memória e os registros que se têm dela são resultantes de um trabalho de seleção e reconstrução implica em dizer que há elementos (episódios, lugares, personagens, símbolos etc.) que são deliberadamente descartados ou silenciados como se nunca houvessem existido. No caso de grupos considerados minoritários na sociedade, como ocorre com as mulheres, inclusive as escritoras, o histórico silenciamento faz parte de uma trajetória de repressões sofridas. Por isso, ao se questionar para que serve a história das mulheres, a historiadora Mary Del-Priore (2012, p. 9), responde: "para fazê-las existir, viver e ser [...]".

Seguindo a linha da crítica desconstrutivista e dos estudos pós-colonialistas, é na interface entre literatura e estudos culturais que Showalter (1998) sustenta que a história da literatura de autoria feminina inglesa não difere daquela de outras subculturas literárias de grupos socialmente minoritários, os quais primeiro imitam o grupo dominante, inclusive reproduzindo seus discursos e valores, em seguida, protestam contra ele e, por fim, buscam uma voz própria. Neste sentido, ela elencou três fases históricas: 1) A fase Feminina, ou de internalização e ressonância dos padrões vigentes (séc. XVII - XIX); 2) a fase Feminista, ou de protestos e defesa de direitos e valores das minorias (1920 - 1960); e 3) a fase Fêmea, na qual as relações de gêneros não são mais centrais à construção das narrativas (a partir de 1970) e há uma busca por identidade própria.

Este estudo foi muito influente, tendo sido aplicado por pesquisadoras de vários países a suas realidades nacionais, incluindo o Brasil. Neste ponto, é importante considerar que, 
embora as primeiras literatas brasileiras conhecidas surjam ainda no século XIX - Beatriz Francisca de Assis Brandão, Clarinda da Costa Siqueira, Delfina Benigna da Cunha e Ana Eurídice Eufrosina de Barandas (DUARTE, 2003; PRADO e FRANCO, 2012) - segundo Rosemberg (2012), é impressionante que tenha havido qualquer escritor brasileiro, não importa o gênero, antes do século XX, tendo em vista os dados do senso de 1871, que revelam que apenas cerca de $19 \%$ dos homens e $11 \%$ das mulheres do país eram alfabetizados.

De todo modo, isto não impediu que, no Brasil, a fase feminina, segundo Xavier (1998 apud ZOLIN, 2005), tenha se iniciado em 1859, com a publicação de Úrsula de Maria Firmina dos Reis. Já a fase Feminista, teria se iniciado em 1944 com Perto do Coração Selvagem de Clarice Lispector. Para a fase Fêmea, Xavier (1998 apud ZOLIN, 2005) aponta apenas que o período inicia a partir dos anos 1990, não estabelecendo, no entanto, um livro que o inaugure. Zolin (2005), por sua vez, defende que esta fase iniciou um pouco antes, ainda em 1984, com a República dos Sonhos de Nélida Piñon.

Quanto a Úrsula, é importante enfatizar que, embora este seja reconhecido como o primeiro romance romântico brasileiro de autoria feminina, a notoriedade alcançada postumamente por sua autora é uma exceção das mais raras. Santiago (2012) aponta que Maria Firmina dos Reis pertence à diminuta lista de escritoras negras reconhecidas pela historiografia literária nacional, da qual também fazem parte Auta de Souza e Maria Carolina de Jesus.

Assim como os textos produzidos por escritoras brancas, as produções destas primeiras literatas negras, são marcadas pela presença de elementos autobiográficos e refletem os sofrimentos de sua condição de mulheres numa sociedade marcadamente patriarcal. Porém, suas penas são agravadas por um contexto profundamente preconceituoso quanto a suas características étnico-raciais.

Embora esta temática persista ao longo do século XX e neste começo do século XXI, como no romance Ponciá Vicêncio ${ }^{5}$ de Conceição Evaristo publicado em 2003, percebe-se uma gradual mudança neste padrão. Escritoras como a dramaturga e cronista Cidinha da Silva, a poetisa Esmeralda Ribeiro, a dramaturga Cristiane Sobral, as poetisas e ficcionistas Lia Vieira e Geni Guimarães, a atriz e poetiza Elisa Lucinda e a romancista Ana Maria Gonçalves, têm produzido textos mais diversos, nos quais são enfocados não somente as dificuldades diárias vividas pelas mulheres negras, mas também seus sonhos e conquistas. De maneira geral, suas personagens são mais complexas, representações diferentes dos estereótipos do passado (SANTIAGO, 2012).

Quanto às escritoras pertencentes aos povos originários, praticamente invisíveis dentre as pouco visíveis, as informações disponíveis são ainda mais escassas devido à desvalorização a que sua literatura tradicionalmente oral tem sido relegada pela civilização letrada.

Tendo em vista este panorama, o objetivo principal deste artigo é investigar o desenvolvimento da literatura paraense de autoria feminina da segunda metade do século XX ao momento atual através da metodologia de pesquisa bibliográfica associada à documental. Os objetivos específicos são: 1) discutir a relação entre o surgimento das tecnologias digitais e mudanças no ciclo de produção e distribuição de livros enquanto produtos do mercado editorial brasileiro; 2) apresentar uma breve revisão acerca de recorrências estilísticas e temáticas em textos literários brasileiros do período; 3) examinar a produção de escritoras paraenses neste

\footnotetext{
5 O romance narra a vida da personagem título no Brasil poucos anos após a abolição da escravidão. A protagonista sai do meio rural para o urbano em busca de melhores oportunidades de vida, mas se vê vítima de todo tipo de alijamento social.
}

PRACS: Revista Eletrônica de Humanidades do Curso de Ciências Sociais da UNIFAP https://periodicos.unifap.br/index.php/pracs ISSN 1984-4352 Macapá, v. 13, n. 1, p. 07-20, jan./abr. 2020 
contexto; 4) identificar iniciativas de disseminação e democratização desta literatura pela sociedade civil.

Na próxima seção, descreveremos resumidamente o surgimento da cultura digital. A seguir, destacaremos seu impacto no fazer literário enquanto fenômeno sociocultural, bem como no mercado editorial.

\section{LITERATURA NO SÉCULO XXI}

A literatura é uma forma de ler, representar e interpretar o mundo, e, ainda, de propor realidades sociais possíveis. Ao representar o real, ela o faz de forma transfigurada pela mente e estilo dos escritores. Isto porque o texto literário é um objeto materializado em um dado momento sócio historicamente delimitado e, portanto, carrega marcas das condições materiais e ideológicas deste momento (CHARTIER, 2010; CANDIDO, 2006).

Ademais, a história mundial da literatura escrita sempre esteve ligada à história do desenvolvimento de artefatos tecnológicos. Seja o binômio lápis e papel, seja um celular com sistema operacional de última geração, as possibilidades de uso e o acesso a estas invenções afetam a forma como se estabelecem as relações sociais numa dada comunidade e, consequentemente, sua produção literária.

Os romances e contos do estadunidense F. Scott Fitzgerald e de seu conterrâneo John Cheever, assim como os do irlandês James Joyce e da inglesa Virginia Woolf, são apenas alguns exemplos de que quando surgiram meios de comunicação de massa como o cinema e o rádio, estes artefatos rapidamente foram incorporados como temas da literatura. Ao mesmo tempo, eles também influenciaram no desenvolvimento de novas técnicas, como, por exemplo, a fragmentação da linguagem e o fluxo de consciência tão comuns nos textos modernistas.

Assim, nada mais previsível que algo semelhante viesse a ocorrer com a invenção dos computadores pessoais, dos sistemas operacionais de fácil utilização e com o surgimento do ciberespaço e da cibercultura. Lévy (2010) explica que:

O ciberespaço (que também chamarei de 'rede') é o novo meio de comunicação que surge da interconexão mundial dos computadores. O termo especifica não apenas a infraestrutura material da comunicação digital, mas também o universo oceânico de informações que ela abriga, assim como os seres humanos que navegam e se alimentam desse universo" (LÉVY, 2010, p. 15-16).

Juntamente com o ciberespaço, desenvolve-se a cibercultura que compreende uma série de valores e modos de pensamento, e de práticas e atitudes que se refletem na maneira como os usuários da rede tanto consomem quanto criam as informações e fontes de entretenimento que nela circulam. Tais práticas abriram caminho para o surgimento de novas formas de produção e circulação da indústria cultural, da qual a literatura faz parte.

Atualmente, um grande número de escritores em atividade, mesmo aqueles que continuam publicando exclusivamente no tradicional suporte do livro físico, utiliza a rede como meio de comunicação com seus leitores. Entre os novatos, é comum a publicação em mídias digitais blogs, plataformas de autopublicação ${ }^{6}$ que permitem o acesso à leitura gratuita (como o

${ }^{6}$ Algumas destas plataformas de autopublicação, como a Amazon e a Clube de Autores, costuma oferecer a possibilidade 
Wattpad) ou paga (como a Amazon7) e, ainda, em redes sociais (como o Facebook) - para a formação de um público leitor antes de fazer uma publicação física, que envolve um investimento financeiro bem mais alto e sem qualquer garantia de retorno. Tem havido também um crescimento no número de autores já consagrados publicando na rede como forma de expandir seu público leitor e, ainda, há escritores (iniciantes e consagrados) publicando exclusivamente livros digitais ${ }^{8}$.

Paralelamente, o surgimento de softwares de edição de textos e de editoração gráfica de operação relativamente simples, bem como o desenvolvimento de técnicas e máquinas mais velozes baratearam os custos de produção dos livros, o que possibilitou a proliferação de pequenas editoras e a oferta aos escritores da possibilidade de pequenas tiragens ${ }^{9}$. Com isso, houve uma ampliação do número de escritores publicando e de títulos disponíveis no mercado. Se por um lado, esta variedade de produtos favorece a leitores de gostos variados, por outro, esta mesma variedade tende a deixá-los desnorteados e representa aos escritores um desafio a mais para atrair a atenção para suas produções. Na disputa por leitores, os escritores contemporâneos, de modo geral, têm se distanciado cada vez mais da figura reclusa a qual tradicionalmente costumavam ser associados e se tornado acessíveis e midiáticos, muitos chegando mesmo a vender suas próprias imagens à frente de seus produtos, incorporados à prática do culto às celebridades (PERRONE-MOISÉS, 2006).

As crescentes demandas da vida urbana, onde o tempo parece cada vez mais exíguo e a facilidade de compras pela rede, conjugados à prolongada crise econômica nacional na corrente década, são outros fatores que influenciaram na crise do modelo de mercado editorial estabelecido e nas relações de produção e consumo de publicações.

Dados da Pesquisa Produção e Vendas do Setor Editorial Brasileiro na última década (2006 - 2016), realizada pela Fundação Instituto de Pesquisas Econômicas (FIPE), informam que, se forem desconsideradas as compras realizadas pelo governo com livros didáticos e paradidáticos, o mercado editorial brasileiro encolheu "de 2006 a 2016 (...) passando dos R \$ 5,01 bilhões (em valores corrigidos) apurados em 2006, para R \$ 3,8 bilhões, em 2016” (MARQUES NETO, 2017), o que corresponde a uma queda de 22,85\%. Isto, porém, não significa necessariamente que as pessoas estejam lendo menos, pois como como ressalta a economista Mariana Bueno, responsável pela pesquisa da FIPE,

A redução nos financiamentos estudantis e a evasão por conta da crise afetaram em cheio esse setor. Com isso, alunos e profissionais da área buscam outras formas de adquirir o material, seja de forma legal, como empréstimos em bibliotecas, seja de forma ilegal, com PDFs que baixam na internet ou fotocópias piratas (BUENO, apud MARQUES NETO, 2017).

\footnotetext{
da impressão de livros físicos sob demanda, o que funciona da seguinte forma: o cliente realiza a compra na plataforma, a empresa envia o material digital para uma gráfica que produz somente a quantia exata solicitada (a partir de um exemplar) e a encomenda é enviada ao cliente através dos correios ou algum outro serviço de entregas. O autor recebe uma porcentagem pela venda que varia de uma plataforma para outra.

7 A hospedagem de livros digitais nesta plataforma internacional, assim como em sua concorrente nacional "Clube de Autores", é gratuita para os autores e o acesso dos leitores é pago. No caso específico da Amazon, existe a possibilidade de ofertar o acesso gratuito, mas somente por 5 dias a cada 90 dias.

${ }^{8}$ No Brasil, o mercado de livros digitais ainda é muito tímido, correspondendo a apenas 1,9\% das vendas do setor segundo dados do Censo do Livro Digital, divulgado em 2017 pela FIPE, CBL e SNEL.

${ }^{9}$ Pequenas tiragens é um termo sem definição precisa, mas costuma se referir a impressão de um número entre 20 e 100 cópias de um livro.
} 
Outra alternativa para aquisição de livros que tem crescido é a compra de usados. Segundo Saturno (2018) em matéria do site Canaltech, somente a plataforma Estante Virtual, que reúne mais de 2.600 sebos e livrarias de todas as regiões do país, vende cerca de 12 mil livros por dia, sendo que $45 \%$ de suas vendas ocorre fora da região Sudeste.

Todo este novo panorama impacta não apenas na produção e circulação da literatura como, também, suscita debates em torno dos temas, procedimentos adotados e do valor estético em si dos textos contemporâneos enquanto formas de arte e de que posição é atualmente ocupada pela literatura de autoria feminina.

Para Perrone-Moisés (2016), as mudanças ocorridas no mercado editorial e a revolução digital se refletiriam mais na quantidade e na qualidade (inferior, na maioria dos casos) da literatura produzida atualmente do que na criação de um novo estilo de época. A teórica defende que não há uma escola pós-modernista, mas sim um modernismo tardio, ao qual ela chama, por falta de termo melhor, de contemporaneidade. Segundo Perrone-Moisés (2016),

Todas estas experiências [intertextualidade, metalinguagem, paródia, fluxo de consciência, fragmentação e representação neutra do real, e autoficção] foram assimiladas pelos escritores contemporâneos, que ora lhes dão uma continuidade, ora as ignoram, praticando tranquilamente qualquer estilo do passado, sem a preocupação modernista com o novo. E essa despreocupação é típica dos escritores contemporâneos, que colhem, tanto no passado quanto no presente, seus temas e modos de expressão (PERRONE-MOISÉS, 2016, p. 45-46).

Além do mais, ela observa que mesmo nas produções exclusivas para o suporte digital, a forma de diagramação dos livros eletrônicos permanece, salvo exceções, a mesma do livro físico. A pesquisadora acrescenta que "a ambição da maioria desses novos autores é ver suas obras publicadas como livros pelas grandes editoras” (PERRONE-MOISÉS, 2016, p. 46) o que pode ser atestado pela profusão de lançamento de novos romances mensalmente.

O recorte para a autoria feminina não parece diferi-la particularmente do que tem ocorrido com as produções literárias atuais em geral, onde a narrativa longa tem prevalecido em termos de prestígio. Com relação aos temas e estilos, se pode observar que as produções mais recentes, provavelmente em decorrência dos novos espaços sociais ocupados pelas mulheres nas últimas décadas, apresentam maior variedade do que nas gerações anteriores. Muito embora prossiga a discussão acerca das relações de gênero, sejam estas em âmbito privado ou público, esta se tem tornado secundária quando comparada às discussões acerca de conflitos de classes e de desafios específicos, sendo estes inerentes a dados locais de fala (origem étnica, classe social e orientação sexual) aos quais pertencem as personagens, coincidindo ou não com a biografia de suas escritoras.

Já com relação a iniciativas institucionais de valorização da literatura e da qualidade estética das obras, os debates são bem mais polêmicos. Perrone-Moisés (2016, p. 265) alerta para o risco de a literatura

perder suas características mais valiosas e de abrigar qualquer tipo de texto escrito, impresso ou eletrônico. Para que ela mantenha um mínimo de especificidade, é preciso que suas qualidades básicas sejam reafirmadas. O que define um texto literário não é sua temática ou sua autoria, mas a forma como o tema é tratado. Por mais respeitáveis que sejam as causas ilustradas e defendidas num texto, não são elas que o tornam literário. Considerar um texto "literatura" porque ele tem um valor político é uma atitude ética, mas não estética. 
Divergindo, Dalcastagnè (2018b) defende a necessidade da promoção da leitura extensiva e da realização de mais estudos acadêmicos com recortes de gênero dada a continuada discrepância no número de autoras e autores estudados. Ela também argumenta que a chamada alta literatura tem seu prestígio oriundo da valorização de alguns modelos - gêneros, procedimentos e estilos de escrita - praticados por um grupo dominante em detrimento dos demais. Segundo a autora, na literatura brasileira dos últimos 40 anos o romance tem sido o gênero de maior prestígio enquanto tema de estudos acadêmicos e de resenhas em espaços de crítica jornalística, o que se contrapõe ao tipo de literatura mais comumente praticado por grupos minoritários em geral, a saber: a poesia, a crônica e o conto.

Em estudo que abrange a literatura brasileira produzida entre os anos 2005 e 2014, ela constatou que o grupo dominante é formado por homens $(70,6 \%)$ brancos $(97,5 \%)$ heterossexuais de classe média vivendo no eixo Rio-São Paulo (60\%) que tendem a construir personagens autorreferentes (DALCASTAGNÈ, 2018a). Seria o caso, segundo ela, de se examinar as produções de outros grupos não apenas pela importância política de ouvir o que o outro tem a dizer sobre si, mas também por sua própria especificidade artística, admitindo a existência e validade de outros modelos estéticos (DALCASTAGNÈ, 2007).

Como se pode inferir, não há um consenso para esta discussão. Neste artigo nos alinhamos com Dalcastagnè ao entender que estudar academicamente a produção de grupos minoritários traz tanto consequências políticas (de médio e longo prazos) quanto epistemológicas aplicadas à área das humanidades ao admitir que há outras formas de saber com suas especificidades que ainda não foram apreendidas pela ciência. Se, por um lado, contribui para romper a invisibilidade a que estes grupos vêm sendo sujeitados, por outro, este tipo de pesquisa influencia no desenvolvimento dos estudos de recepção de textos literários, tratando-se não apenas de uma questão ética, mas também de busca por compreensão das inovações e/ou renovações que compõe a diversidade estética na produção literária atual.

A seguir, trataremos sobre a literatura produzida por mulheres no estado do Pará. Discorremos brevemente acerca de seu tradicional lugar de não prestígio e de como grupos da sociedade civil têm atuado nos mundos físico e digital no sentido de modificar este quadro. Apresentaremos também um panorama das produções atuais.

\section{LITERATURA PARAENSE DE AUTORIA FEMININA}

A produção de autoria feminina no Brasil, segundo Zilberman (2008), torna-se abundante a partir do século XIX. Entretanto, em 1950, no livro "A História da Literatura Brasileira" consta o nome de apenas uma escritora. Espantosamente, como informa Zolin (2005, p. 276), este livro foi escrito por uma mulher.

Iniciativas têm sido empreendidas no sentido de incluir a fala "delas" na história literária nacional. Exemplos disso são o lançamento, em 1999, da antologia "Escritoras Brasileiras do Século XIX", contendo estudos sobre 52 autoras, e do Dicionário Crítico de Escritoras Brasileiras, em 2002, no qual são mencionados 1400 nomes. Embora se reconheça a expressividade destes números, eles ainda não dão conta da totalidade de escritoras em atividade no período.

Quando o assunto são as escritoras paraenses, a invisibilidade é ainda maior. Segundo Vidal (2012), no livro "Introdução à Literatura no Pará", publicado em 1990, constam duas listas de 432 escritores paraenses nascidos durante a primeira metade do século XX, nas quais: a primeira contém 167 nomes cujas datas de nascimento foram verificadas e dentre os quais apenas

PRACS: Revista Eletrônica de Humanidades do Curso de Ciências Sociais da UNIFAP https://periodicos.unifap.br/index.php/pracs ISSN 1984-4352 Macapá, v. 13, n. 1, p. 07-20, jan./abr. 2020 
20 são femininos $(11,97 \%)$ e a segunda que contém 265 nomes cujas datas de nascimento não foram verificadas, dos quais apenas 61 são femininos $(23 \%)$.

No esforço de perseguir a audição dessas vozes que se encontram nas margens da produção literária, o Grupo de Estudos e Pesquisas Eneida de Moraes (GEPEM) tem sobressaído. Santos e Ribeiro (2013, p. 90) informam que

algumas pesquisadoras do GEPEM têm direcionado ações nesta perspectiva, a exemplo: o Inventário das Práticas e Saberes das Mulheres Paraenses, no Campo da Literatura e de outras Artes: 1870/1970 realizado entre os anos 2000-2001, por Maria Luzia Álvares e Eunice Santos; os estudos específicos de Maria de Fátima Nascimento a respeito da poética de Olga Savary (2005-2006), incluindo entrevistas e acervo parcial; os de Eunice Ferreira dos Santos (2004) focalizando a escritura e a militância política de Eneida de Moraes, com reunião de 5500 peças éditas e inéditas, e a pesquisa intitulada Percursos Literários de Escritoras Paraenses: "cem anos de solidão" (1900-2000), a ser concluída em 2008, objetivando organizar uma antologia com verbetes bibliográficos e amostra textual (prosa e verso) de quinze escritoras paraenses sem inclusão literária.

Além de haver catalogado um expressivo número de literatas e suas respectivas produções (em prosa e verso), as pesquisadoras do GEPEM também têm se empenhado em problematizar os fatores que influenciam na inserção ou ausência destas literatas no cânone regional, o qual tem se limitado a admitir apenas quatro nomes femininos: Eneida de Moraes, Lindanor Celina, Maria Lúcia Medeiros e Olga Savary. Destas, somente a última segue viva.

O Quadro 1 abaixo apresenta algumas informações acerca destas autoras.

Quadro 1 - Literatas paraenses incorporadas ao cânone regional e suas respectivas produções

\begin{tabular}{|c|c|c|}
\hline ESCRITORA & PRINCIPAIS LIVROS & MINIBIOGRAFIA \\
\hline $\begin{array}{l}\text { Eneida de Moraes } \\
(1904-1971)\end{array}$ & $\begin{array}{l}\text { Cão da Madrugada (1954) } \\
\text { Aruanda (1957) } \\
\text { Banho de Cheiro (1962) }\end{array}$ & $\begin{array}{l}\text { Jornalista nascida em Belém, seu livro de estreia } \\
\text { foi de poesia, porém, a maior parte de sua pro- } \\
\text { dução pertence ao gênero crônica. Seus textos } \\
\text { retratam momentos de sua vida em Belém e no } \\
\text { Rio de Janeiro, bem como seu envolvimento } \\
\text { com o cenário político da época. }\end{array}$ \\
\hline $\begin{array}{l}\text { Lindanor Celina } \\
(1917-2003)\end{array}$ & $\begin{array}{l}\text { A Menina que Veio de Itaiara (1963) } \\
\text { Estrada do Tempo-foi (1971) } \\
\text { Breve Sempre (1973) } \\
\text { Afonso Contínuo, santo de altar (1986) } \\
\text { A Viajante e seus Espantos (1988) } \\
\text { Diário da Ilha: crônicas (1992) } \\
\text { Eram Seis Assinalados (1994) }\end{array}$ & $\begin{array}{l}\text { Romancista e cronista nascida em Castanhal, } \\
\text { mudou-se para Bragança ainda criança. Após } \\
\text { romper o casamento, mudou-se com os três fi- } \\
\text { lhos para a França, onde viveu por } 30 \text { anos, } \\
\text { tendo lecionado literatura brasileira na Univer- } \\
\text { sidade de Lile. Seus primeiros três livros apre- } \\
\text { sentam claras referências à terra de sua infância. }\end{array}$ \\
\hline $\begin{array}{l}\text { Maria Lúcia Medeiros } \\
(1942-2005)\end{array}$ & $\begin{array}{l}\text { Zeus ou a Menina e os Óculos (1988) } \\
\text { Velas para Quem? (1990) } \\
\text { Quarto de Hora (1994) } \\
\text { Horizonte Silencioso (2000) }\end{array}$ & $\begin{array}{l}\text { Contista e poeta nascida em Bragança. Na ado- } \\
\text { lescência, mudou-se para Belém, onde estudou } \\
\text { e se tornou professora e pesquisadora da Uni- } \\
\text { versidade Federal do Pará. Muitos de seus con- } \\
\text { tos se inscrevem na tradição do realismo fantás- } \\
\text { tico latino-americano enquanto outros tantos } \\
\text { retratam situações do quotidiano da região. }\end{array}$ \\
\hline $\begin{array}{l}\text { Olga Savary } \\
(1933-)\end{array}$ & $\begin{array}{l}\text { Espelho Provisório (1970) } \\
\text { Altaonda (1979) } \\
\text { Magma (1982) } \\
\text { Linha d'água (1987) } \\
\text { Retratos (1989) } \\
\text { O Olhar Dourado do Abismo (1997) }\end{array}$ & $\begin{array}{l}\text { Nascida em Belém, esta poeta e contista que } \\
\text { tem mais de vinte livros publicados, foi a pri- } \\
\text { meira mulher brasileira a publicar um livro de } \\
\text { poesia erótica (Magma). Tradutora e crítica lite- } \\
\text { rária, vive há muitos anos no Rio de Janeiro. }\end{array}$ \\
\hline
\end{tabular}


É indiscutível o valor do legado deixado pelas quatro escritoras supracitadas, conforme Quadro 1, coincidentemente, todas mulheres brancas de classe média ou alta. A literatura paraense, porém, está longe de resumir-se a elas. Novas escritoras surgem anualmente, porém, pouquíssimas alcançam algum reconhecimento devido a dificuldades de divulgação e circulação.

Neste sentido, as pesquisas intituladas "Escritoras Paraenses em Prosa e Verso: os protocolos de inserção da autoria feminina no cânone escolar de Belém/PA (2005-2007)" e "Autoria Feminina na História Literária do Pará: diálogos com a educação básica (2008- 2010)" investigam o panorama atual e propõe que a escola ocupe um papel central enquanto mediadora de leitura para seus educandos. Santos e Ribeiro (2013) partem do pressuposto de que os professores de língua portuguesa exercem uma grande influência na disseminação de conhecimento acerca de escritores e suas obras, o que implica em que professores que desconhecem escritoras não tem como dá-las a conhecer.

Portanto, o problema central, estaria na formação destes professores, visto que as três universidades investigadas que oferecem a licenciatura em Letras, não incluíam, a não ser eventualmente, escritoras paraenses em seus percursos formativos. Neste ponto, Santos e Ribeiro (2013) concordam com a proposição de Dalcastagnè (2007) de que haveria uma necessidade de intensificar a atuação das universidades no sentido de conferir validação acadêmica a um maior número de escritoras através da realização de trabalhos de resgate e recepção crítica sobre suas obras.

Esta validação acadêmica, defendem Santos e Ribeiro (2013), contribuiria para valorizar as produções de autoria feminina, movimentando o mercado editorial que seria, como consequência, estimulado a reeditar títulos esgotados agora em demanda. Além disso, os professores mediadores de leitura tenderiam a incluir obras de escritoras paraenses em seus planejamentos de aula o que acabaria por requerer que as escolas adquirissem tais livros para suas bibliotecas. Desta forma, este percurso contribuiria para a circulação destas produções por toda a comunidade escolar. Adicionalmente, novas escritoras, tomando como exemplo a notoriedade de escritoras que as antecederam, bem como, por verem na atividade a possibilidade de algum retorno financeiro, seriam estimuladas a também começar a publicar.

Quanto ao papel do ciberespaço na produção e circulação da literatura, observa-se que se, por um lado, adentrar neste mercado tornou-se mais democrático, por outro, é certo que tal democratização é imperfeita, visto que o acesso à rede está longe de incluir a todos. Segundo dados do IBGE (2016), cerca de 35,3\% dos brasileiros continuam sem a acessar. Na região Norte, este número chega a 38,6\% da população. Ainda assim, diversos escritores e grupos mais ou menos organizados têm se apropriado destas facilidades para tornar públicas suas produções.

Um exemplo de como a rede digital pode ser usada na prática para dar maior visibilidade à autoria feminina é o grupo Roda de Escritoras Paraenses. Fundado pela escritora, atriz e pesquisadora Carol Magno em 2016, o grupo do Facebook reúne atualmente 127 mulheres escritoras ${ }^{10}$ paraenses ou residentes há muitos anos no Estado, algumas fora dele. O objetivo da iniciativa, segundo sua fundadora, foi descobrir quem seriam as outras escritoras conterrâneas suas em atividade, produzindo em qualquer que seja o gênero literário, e contribuir para aproximá-las umas das outras, rompendo o ciclo de desconhecimento que predomina. Dadas as dificuldades de deslocamento geográfico num estado das dimensões do Pará $(1.248 .000$ km²),

${ }^{10}$ Dado de 03 de fevereiro de 2020.

PRACS: Revista Eletrônica de Humanidades do Curso de Ciências Sociais da UNIFAP 
as reuniões presenciais do grupo só ocorrem eventualmente, normalmente contando com apenas uma pequena parte das integrantes.

O encontro do dia 06 de maio de 2018 teve como uma das questões centrais a quase ausência de vozes femininas na Feira Pan-amazônica do Livro que seria realizada logo no mês seguinte (AMORIM, 2018). Após muita discussão, alguns encaminhamentos foram dados que resultaram na organização de uma antologia de poesia, a qual reuniu 83 escritoras éditas e inéditas, bem como, numa feira literária alternativa (RODRIGUES, 2018). Dentre as integrantes mais ativas do grupo ao longo do ano de 2019 constam: Aldemira Aguiar, Giselle Ribeiro, Heliana Barriga, Luciana Brandão Carreira, Mayara La-Rocque e Rita Melém.

Quadro 2 - Literatas da Roda de Escritoras Paraenses com produções expressivas em 2019

\begin{tabular}{|c|c|c|}
\hline ESCRITORAS & PRINCIPAIS LIVROS & MINIBIOGRAFIA \\
\hline Aldemira Aguiar & $\begin{array}{l}\text { Respingos de Sabedoria (2014) } \\
\text { Pelos Caminhos (2017) } \\
\text { IV Anuário da Poesia Paraense (2018) }\end{array}$ & $\begin{array}{l}\text { Nascida em Bacabal (MA), vive em Marabá desde } \\
\text { 1976. É também artista plástica e participa de várias } \\
\text { associações literárias, dentre as quais a Academia de } \\
\text { Letras do Brasil - Seccional Sul e Sudeste do Pará. } \\
\text { A espiritualidade cristã é um dos temas mais recor- } \\
\text { rentes em sua poesia lírica. }\end{array}$ \\
\hline Giselle Ribeiro & $\begin{array}{l}\text { Objeto Perdido (2004) } \\
69 \text { (2009) } \\
\text { Pequeno Livro de Poemas para Vestir } \\
\text { Bem (2011) } \\
\text { Isto não é um Livro, Isto é um Cara- } \\
\text { col (2013) } \\
\text { A Princesa Sem Dons para Tamanha } \\
\text { Felicidade (2019) }\end{array}$ & $\begin{array}{l}\text { Nascida em Capanema, a poeta mudou-se para Be- } \\
\text { lém ainda na infância. Sua poética abrange do ero- } \\
\text { tismo à busca metafísica por um sentido para a exis- } \\
\text { tência. Contadora de histórias e pesquisadora da re- } \\
\text { lação entre literatura, mediação de leitura e ludici- } \\
\text { dade, estreou recentemente na literatura voltada ao } \\
\text { público infantil. É professora da área de estudos li- } \\
\text { terários na UFPA desde } 1996 \text {. Também é ligada ao } \\
\text { Movimento Sociedade dos Poetas Vivos e ao Movi- } \\
\text { mento dos Contadores de Histórias da Amazônia. }\end{array}$ \\
\hline Heliana Barriga & $\begin{array}{l}\text { A Abelha Abelhuda (1994) } \\
\text { Perereca Sapeca (1996) } \\
\text { O livro da Malta de Poetas Folhas e } \\
\text { Ervas (1999 - antologia) } \\
\text { Luz (2004 - antologia) } \\
\text { O livro da Malta III (2008 - antolo- } \\
\text { gia) } \\
\text { Eco Poético (2014 - antologia) }\end{array}$ & $\begin{array}{l}\text { Agrônoma, sanfoneira, compositora e poeta, escre- } \\
\text { veu um grande número de livros infantis. Mesmo } \\
\text { quando escreve para o público adulto, sua poesia é } \\
\text { marcadamente musical, apresentando brincadeiras } \\
\text { com as palavras nas quais se reflete uma preocupa- } \\
\text { ção com seu significado tanto quanto (ou até mais) } \\
\text { com sua sonoridade. Juntamente com Roseli Sousa, } \\
\text { Antônio Juraci Siqueira, Benilton Cruz, Oona Agaia } \\
\text { e Walber Pereira formou o coletivo Malta de Poetas } \\
\text { Folhas e Ervas que revolucionou a cena literária be- } \\
\text { lenense em meados da década de } 1980 \text {. Também é } \\
\text { ligada a outros grupos, como o Movimento Socie- } \\
\text { dade dos Poetas Vivos e o Movimento Literário Ex- } \\
\text { tremo Norte. }\end{array}$ \\
\hline $\begin{array}{l}\text { Luciana Brandão Car- } \\
\text { reira }\end{array}$ & $\begin{array}{l}\text { Entre (2014) } \\
\text { Poeta, Mostra A tua Cara vol. } 11 \\
\text { (2014 - antologia) } \\
\text { A Letra da Água (2017) } \\
\text { IV Anuário da Poesia Paraense } \\
\text { (2018) }\end{array}$ & $\begin{array}{l}\text { Psiquiatra e professora universitária com pesquisas } \\
\text { que estudam a interface entre artes e psicologia, esta } \\
\text { poeta nascida em Belém, participa do núcleo edito- } \\
\text { rial das revistas literárias Polichinello e Caliban. Sua } \\
\text { poesia aproxima-se do estilo simbolista pela sineste- } \\
\text { sia gerada através de jogos de aliteração e assonân- } \\
\text { cia, bem como pela subjetividade e o apelo ao oní- } \\
\text { rico. }\end{array}$ \\
\hline Mayara La-Rocque & $\begin{array}{l}\text { Atravessa a tua viagem (2016) } \\
\text { Uma luminária pensa no céu (2017) }\end{array}$ & $\begin{array}{l}\text { Licenciada em Língua Francesa, esta contista, cro- } \\
\text { nista e poeta é natural de Belém. Colaborou com a } \\
\text { revista KamiKases e destacou-se no Prêmio } \\
\text { PROEX de Literatura por dois anos consecutivos } \\
\text { nas categorias poesia e prosa. Além de escrever, mi- } \\
\text { nistra oficinas de produção literária. }\end{array}$ \\
\hline
\end{tabular}




\begin{tabular}{|l|l|l|}
\hline Rita Melém & $\begin{array}{l}\text { Auto-poemas (2006) } \\
\text { Portapalavras (2008) } \\
\text { Eco Poético (2014-antologia) } \\
\text { O Divino Feminino Liberto (2019- } \\
\text { antologia) }\end{array}$ & $\begin{array}{l}\text { Pedagoga e mediadora de leitura, nascida em Belém, } \\
\text { a poeta integra o Movimento Literário Extremo } \\
\text { Norte e é ativista pelos direitos humanos. Idealiza- } \\
\text { dora e fundadora juntamente com sua esposa, a } \\
\text { também escritora Cris Rodrigues, do projeto da Bi- } \\
\text { blioteca Itinerante BombomLer. Sua produção é } \\
\text { composta predominantemente por poemas líricos } \\
\text { breves. }\end{array}$ \\
\hline
\end{tabular}

As seis autoras do quadro acima seguem vivas e produzindo predominantemente poemas de formas livres. Além dos títulos mencionados, todas têm participação em outras antologias e/ou revistas literárias.

Outro exemplo é a formação de clubes de leitura. Embora não se trate de uma prática nova, o diferencial dos clubes atuais é que eles tendem a se formar ou, ao menos crescer, através de redes sociais. Um grupo que merece destaque é a Rede Amazônia Literária ${ }^{11}$. Surgida a partir da aproximação espontânea de bibliotecas comunitárias em funcionamento em Belém e sua região metropolitana - uma delas, Espaço Cultural Nossa Biblioteca no bairro do Guamá, em funcionamento há cerca de 40 anos, segundo informa a página do grupo no Facebook ${ }^{12}$-, a rede é dirigida por professores e pedagogos que atuam na educação básica. Em suas variadas ações de mediação de leitura, incluem-se clubes de leitura e rodas de conversa com escritores e escritoras locais.

Outro grupo que chama a atenção neste sentido é o Leia Mulheres Belém ${ }^{13}$. Em atividade desde maio de 2016, o grupo de pessoas que gostam de ler utiliza o Facebook e o Instagram para discutir e anunciar os temas de suas reuniões presenciais mensais, nas quais é cumprida a atividade principal do movimento: discutir livros escritos por mulheres como forma de estimular a leitura de escritos de autoria feminina. Em ambos os casos, não há um foco específico em autoras locais, mas estas também são contempladas nas programações.

\section{CONSIDERAÇÕES FINAIS}

A escrita paraense de autoria feminina, mesmo a produzida por mulheres brancas de classe média, permanece na condição de literatura marginal, no sentido de ser tradicionalmente considerada uma literatura menor, de qualidade inferior. Quanto aos textos de escritoras negras, ameríndias e afro-ameríndias, que compõe grande parcela da população local, o espaço é ainda mais restrito. Não se pode deixar de apontar que questões ainda mais complexas se colocam quando a pesquisa envolve recortes como a classe social e a orientação sexual das escritoras.

Embora estas constatações não sejam animadoras e o número de escritoras paraenses conhecidas seja muito pequeno, verifica-se que tem havido iniciativas da sociedade civil e institucionais para ampliar o cânone. Os dados do GEPEM indicam que nas últimas duas décadas, houve o crescimento na quantidade de estudos acadêmicos que se debruçam sobre a literatura local.

Quanto aos gêneros praticados em solo paraense, embora, o romance ainda detenha maior

11 Ligada à Rede Nacional de Bibliotecas Comunitárias.

12 Disponível em <https://web.facebook.com/pg/rbcamazonialiteraria/about/> acesso em 23/07/2019.

13 Trata-se da versão local do movimento iniciado despretensiosamente pela escritora britânica Joanna Walsh em 2014 no Twitter com a criação da hashtag \#readwomen2014. Atualmente, há 139 grupos ligados a este movimento só no Brasil, sendo três no estado do Pará, segundo dados obtidos no site oficial https://leiamulheres.com.br/sobre-nos/. 
prestígio social, nota-se que o conto, a crônica e a poesia mantêm um espaço constante, no qual a literatura local (independente do gênero dos autores) tem sido prolífica. O recurso à memória como fonte de inspiração explícita ou profundamente reconfigurada também se mostra recorrente em textos como os de Eneida de Moraes, Lindanor Celina, Maria Lúcia Medeiros e Rita Melém. Suas reminiscências da terra natal com seus habitantes, paisagens, tradições e sabores conferem às suas produções uma singularidade regional que, se mais difundida, muito poderia contribuir para a renovação estética da literatura nacional.

Por fim, pode-se observar que o mercado editorial local não difere do nacional neste momento de transformação. Seja para publicar-se, para se promover ou para obter livros físicos ou digitais de forma legal (ou não), é inegável que o acesso à rede de computadores tornou-se essencial. Portanto, um dos pontos que não pode ser excluído no debate é a democratização do acesso à rede de computadores. A julgar pela popularidade dos grupos de leitura, isto não reduz, porém, a importância dos encontros e ações de promoção do livro e da leitura no mundo físico.

\section{REFERÊNCIAS}

AMORIM, Paloma Franca. Evento literário no Pará vai na contramão dos esforços do setor. Folha de São Paulo. Opinião. 25 de abr. de 2018. Disponível em: <https://www1.folha.uol.com.br/ilustrada/2018/04/evento-literario-no-para-vai-na-contramao-dos-esforcosdo-setor.shtml>. Acesso em 21/07/2019.

BONNICI, Thomas. Teoria e Crítica Literária Feminista: conceitos e tendências. Maringá: EDUEM, 2007.

BOSI, Ecléa. Memória e Sociedade: lembranças de velhos. 3.ed. São Paulo: Companhia das Letras, 1994.

BRANCO, Lúcia Castelo; BRANDÃO, Ruth Silviano. A Mulher Escrita. 2.ed. Rio de Janeiro: Lamparina, 2004.

CHARTIER, Roger. A História ou a Leitura do Tempo. 2. ed. Belo Horizonte: Autêntica, 2010 .

CANDIDO, Antônio. Literatura e Sociedade. 9. ed. Rio de Janeiro: Ouro Sobre Azul, 2006. DALCASTAGNÈ, Regina. A auto-representação de grupos marginalizados: tensões e estratégias na narrativa contemporânea. Letras de Hoje. Porto Alegre, v. 42, n. 4, p. 18 31, dezembro 2007.

DALCASTAGNÈ, Regina. Quem é sobre o que escreve o autor brasileiro. [entrevista condida a] MASSUELA, Amanda. Revista Cult. 05 de fev. de 2018(a). Literatura. Disponível em <https://revistacult.uol.com.br/home/quem-e-e-sobre-o-que-escreve-o-autor-brasilei ro/>. Acesso em 23/07/2019.

DALCASTAGNÈ, Regina. A crítica literária em periódicos brasileiros uma aproximação. In Estudos de literatura brasileira contemporânea, n. 54, p. 195-209, maio/ ago. 2018b.

DEL PRIORE, Mary. (Org.). História das mulheres no Brasil. 10. ed. São Paulo: Contexto, 2012.

DUARTE, Constância Lima. Feminismo e literatura no Brasil. Estudos Avançados. São Paulo, v.17, n 49. Set./Dez. 2003.

EVARISTO, Conceição. Ponciá Vincêncio. Belo Horizonte: Maza Edições, 2003.

FUNDAÇÃO INSTITUTO DE PESQUISAS ECONÔMICAS. Câmara Brasileira do Livro; 
Sindicato Nacional de Editores de Livros. Censo do Livro Digital: ano base 2016. Disponível em: <https://snel.org.br/wp/wp-content/uploads/2018/02/Apresentacao-Censo-do-Livro -Digital.pdf $>$ Acesso em 19/07/2019.

HALBWACHS, Maurice. A memória coletiva. Trad. de Beatriz Sidou. São Paulo: Centauro, 2006.

IBGE, Diretoria de Pesquisas, Coordenação de Trabalho e Rendimento. Pesquisa Nacional por Amostra de Domicílios contínua, 2016. Disponível em: < https://agenciadenoticias. ibgegov.br/media/com_mediaibge/arquivos/c62c9d551093e4b8e9d9810a6d3bafff.pdf>.

Acesso em 18/07/2019.

LÉVY, Pierre. Cibercultura. Trad. Carlos Irineu da Costa. São Paulo: Editora 34, 1999.

MAINGUENEAU, Dominque. Gênese dos Discursos. Trad. Sírio Possenti. Curitiba: Criar Edições, 2005.

MARQUES NETO, Leonardo Ferreira. Indústria editorial encolheu 17\% na última década. Publishnews. 23 de maio de 2017. Mercado. Disponível em: <https://www.publishnews.com.br/materias/2017/05/23/industria-editorial-encolheu-17-na-ultima-decada $>$.

Acesso em 19/07/2019.

POLLAK, Michael. Memória, esquecimento, silêncio. In: Estudos Históricos. Trad. Dora Rocha Flaksman. Rio de Janeiro, vol. 2, n. 3, 1989, p. 3-15

RODRIGUES, Aline. Literatura de Mulher para Mulher. Diário do Pará. Caderno Você, p. 4. Belém, 04 de jun. de 2018. Disponível em: < http://digital.diariodopara.com.br/web/?sta te $=$ zoom\&data $=04 / 06 / 2018 \&$ pagina $=24>$. Acesso em 21/07/2019.

ROSEMBERG, Fúlvia. Educação: Mulheres educadas e a educação de mulheres. In: PINSKY, Carla; PEDRO, Joana M. (orgs). Nova História das Mulheres no Brasil. São Paulo: Contexto, 2012. p. 333-359.

SANTIAGO, Ana Rita. Vozes Literária de Escritoras Negras. Cruz das Almas: UFRB, 2012. SANTOS, Eunice Ferreira dos; RIBEIRO, Lilian Adriane dos Santos. A Escritura Literária das Mulheres Paraenses: recepção entre leitores/as e cânone. ITABAIANA: GEPIADDE. Ano 07, vol. 14, jul/dez de 2013.

SATURNO, Ares. Livrarias do Século XXI: as transformações do mercado editorial brasileiro. Canaltech. 17 de dez. de 2018. Disponível em: <https://canaltech.com.br/e-commerce/livrarias-do-seculo-xxi-as-transformações-do-mercado-editorial-brasileiro-126859/>. Acesso em 21/07/2019.

SHOWALTER, Elaine. Twenty Years on: "A Literature of Their Own" Revisited. NOVEL: A Forum on Fiction, Vol. 31, No. 3, Thirtieth Anniversary Issue: III (Summer, 1998), p. 399413.

PRADO, Maria Lígia; FRANCO, Stella Scatena. Cultura e Política: Participação Feminina no Debate Público Brasileiro. In: PINSKY, Carla; PEDRO, Joana M. (orgs). Nova História das Mulheres no Brasil. São Paulo: Contexto, 2012. p. 194-217.

VIDAL, Claudia Valeria França. Erotismo Feminino: estudo de um conto de Maria Lúcia Medeiros. In: A Palavrada. Bragança - PA. Número 2, julho-dezembro/2012. p. 50-64.

VIDAL, Claudia Valeria França. As Fantásticas Mulheres de A Casa dos Espíritos de Isabel Allende. Revisa A Palavrada, n. 11, v. 2, 2017, p. 420-438.

ZOLIN, Lúcia Osana. Crítica Feminista. In: BONNICI, Thomas; ZOLIN, Lúcia Osana (orgs.). Teoria Literária: abordagens históricas e tendências contemporâneas. 2. ed. Maringá: EDUEM, 2005, p. 181-204. 